\title{
A COBERTURA DA REVISTA BIZZ SOBRE A BANDA PEARL JAM: UMA ANÁLISE SOB A ÓTICA DOS ESTUDOS CULTURAIS
}

\author{
MÁRCIO FARIAS DE MELLO \\ Universidade Federal de Pelotas \\ Pelotas, Rio Grande do Sul, Brasil \\ e-mail: marcio.mello@atlantida.com.br \\ FÁBIO SOUZA DA CRUZ \\ Universidade Federal de Pelotas \\ Pelotas, Rio Grande do Sul, Brasil \\ e-mail: fabiosouzadacruz@gmail.com
}


A COBERTURA DA REVISTA BIZZ SOBRE A BANDA PEARL JAM: UMA ANÁLISE SOB A ÓTICA DOS ESTUDOS CULTURAIS

Resumo: O trabalho faz uma análise, sob a luz dos estudos culturais, de dois textos extraídos das edições 84 e 101, da revista Bizz, que trouxe em suas capas e matérias centrais, a banda norte-americana Pearl Jam. A partir de uma abordagem qualitativa, esse trabalho contempla as categorias aventadas por Douglas Kellner (2001): Horizonte Social, Campo Discursivo e Ação Figural, fazendo uma análise da real intenção do discurso midiático. Palavras Chaves: Revista Bizz; Pearl Jam; Jornalismo de revista; Estudos culturais.

LA COBERTURA DE LA REVISTA BIZZ DE LA BANDA PEARL JAM: UN ANÁLISIS DESDE LA PERSPECTIVA DE LOS ESTUDIOS CULTURALES

Resumen: El trabajo analiza, a la luz de los estudios culturales, dos textos extrae de temas 84 y 101, la revista Bizz, que reunió en sus portadas y las materias básicas, la banda estadounidense Pearl Jam. Desde un enfoque cualitativo, este trabajo incluye las categorías aventadas por Douglas Kellner (2001): Horizonte social, El campo del discurso y la Acción figurative, haciendo un análisis de la verdadera intención del discurso mediático. Palabras clave: Bizz revista; Pearl Jam; periodismo revista; estudios culturales.

THE BIZZ MAGAZINE COVERAGE OF THE BAND PEARL JAM: AN ANALYSIS FROM THE PERSPECTIVE OF CULTURAL STUDIES

Abstract: The work analyzes, in the light of cultural studies, two texts extracted from issues 84 and 101, the Bizz magazine, which brought on their covers and core subjects, the American band Pearl Jam. From a qualitative approach, this work includes the categories aventadas by Douglas Kellner (2001): Social Horizonte, Discourse Field and Figural action, making an analysis of the real intent of the media discourse. Key Words: Bizz Magazine; Pearl Jam; magazine journalism; cultural studies. 


\section{INTRODUÇÃO}

A revista Bizz foi uma publicação mensal especializada em conteúdo sobre música. Editada no Brasil, entre os anos de 1985 e 2007, sua existência foi permeada por inúmeras modificações em seu padrão editorial e estético, oscilando ao longo do tempo, de acordo com o revezamento de editores e repórteres que passaram por sua redação.

No início da década de 90, a cena musical que permeava o Brasil, era a de grupos como Paralamas do Sucesso, Legião Urbana, Titãs e Barão VermeIho, bandas essas, que se destacaram na primeira edição do festival Rock in Rio ${ }^{1}$. Já nos Estados Unidos, mais especificamente no noroeste, na cidade de Seattle, um movimento surgia, tendo como fio condutor, discursivo e ideológico, a música, sobretudo através das “bandas de garagem”. Inúmeros fatores, até mesmo o próprio movimento de globalização, fizeram com que o Movimento Grunge ${ }^{2}$, estabelecesse um perfil, desenhando, assim, os traços de um movimento de onde emergiram inúmeras bandas, como Nirvana, Soundgarden e Pearl Jam, sendo, essa última, objeto de estudo do presente trabalho.

Ao longo deste trabalho, procurou-se construir um pano de fundo, expondo os objetos que, supostamente aglutinarão o corpo da análise a ser desenvolvida, com base nos Estudos Culturais de Douglas Kellner³ . A metodologia a ser utilizada, abrange as categorias de análise proposta por Kellner (Horizonte social, Campo discursivo e Ação figural). Esse fundamento teórico é base para e exploração textual das matérias extraídas da revista Bizz. De uma forma geral, o trabalho propõe-se a analisar o modo como a mídia produz a informação, tomando como referencia a proposta metodológica dos Estudos Culturais críticos, discutida pelo pesquisador Douglas Kellner.

1 "O Rock in Rio foi realizado pela primeira vez na cidade do Rio de Janeiro, Brasil entre 11 e 20 de janeiro de 1985... Entre 18 e 26 de janeiro de 1991, aconteceu o Rock in Rio II. [...] Após novo hiato, o ano de 2001 viu a realização do Rock in Rio III, nos dias 12 a 14 e 18 a 21 de janeiro." (Disponível em: <http://rockinrio2011.com.br/historia.htm>. Acesso em: 07 nov. 2011).

2 Traduzido para o português como "Sujo"

3 Professor de Filosofia da Universidade do Texas, tendo inúmeras publicações, desde periódicos, ensaios, participações em eventos e livros. Suas categorias de análise, dentro dos estudos culturais críticos, servem como base metodológica para o trabalho aqui desenvolvido. 


\section{CARACTERIZANDO OS OBJETOS DE ESTUDO}

O processo de avanço tecnológico, nos dias de hoje, tem sido evidenciado, principalmente, através da evolução dos veículos por onde o produto editorial circula. Desde a Prensa de Gutenberg'1, até a internet, os veículos que servem como substratos para a circulação da informação, traduzem, editorialmente, os fatos e acontecimentos, de acordo com a linguagem proposta pelos mesmos. Assim, o rádio, a televisão, os jornais, as revistas e a internet propõem formatos diferentes de veiculação dos acontecimentos, veiculando-os a partir de características próprias, em termos de conteúdo, aprofundamento da informação, linguagem, interesse e produção.

O termo "revista" surgiu a partir do século XVI, na Inglaterra, quando um formato de periódico, diferente dos jornais diários, passou a ser produzido de forma a contemplar os assuntos em voga na época com maior profundidade. A evolução gradual das publicações do tipo revista até os dias de hoje, perpassa uma trajetória paralela aos avanços em termos de desenvolvimento econômico dos países, à diminuição do analfabetismo e ao crescente interesse em desenvolver as ideias em torno de assuntos especializados.

No Brasil, a história das revistas começa no início do século XIX, com o lançamento da primeira revista brasileira em 1812, chamada As Variedades ou Ensaios de Literatura. Como o crescimento industrial do Brasil, no inicio do século XX, era exponencial, as revista que surgem passam a ter conotação segmentada, ligadas às áreas de maior fomento industrial no país, como a Revista de Automóvel, em 1911. Até os dias atuais várias foram às publicações de sucesso editorial, dos mais variados gêneros, como: O Cruzeiro, revista de variedade de Assis Chateaubriand ${ }^{2}$, (1928 até a década de 70) e Manchete, da editora Bloch. Surge, em 1968, permanecendo ativa até os

\footnotetext{
1 Johannes Gensfleisch, conhecido como Johannes Gutenberg, nasceu provavelmente em 1397 e é considerado o criador do processo de impressão com tipos móveis, a tipografia; (Disponível em: <http://educacao.uol.com.br/biografias/johannes-gutenberg. jhtm>. Acesso em: 5 out. 2011)

2 Francisco de Assis Chateaubriand Bandeira de Melo, mais conhecido por Assis Chateaubriand ou por Chatô (depois da biografia de Fernando Morais), foi um dos homens mais influentes do Brasil nas décadas de 1940 e 50. Dono de um império jornalístico - os Diários Associados -, que chegou a reunir dezenas de jornais, revistas e estações de rádio, foi também pioneiro da televisão no Brasil, criando a TV Tupi em 1950. (Disponível em: <http://educacao.uol.com.br/biografias/assis-chateaubriand.jhtm>. Acesso em: 24 out. 2011)
} 
dias de hoje, aos moldes da revista norte-americana Time, a revista de notícias e informações Veja, de publicação semanal. No trilho e moldes da revista Veja surgiram também as revistas Isto é, senhor e Época. Contemplando o universo feminino, nascem Manequim, em 1959, e Cláudia, em 1961. Já no campo dos esportes, a revista Placar, lançada em 1970, acabou sendo, até hoje, a experiência de maior sucesso editorial nesse segmento.

\subsection{REVISTA BIZZ}

Em 1985, foi realizada a primeira edição do festival de música Rock n’ Rio, onde se apresentaram diversas bandas e artistas nacionais e internacionais. Naquela ocasião, foi realizada, junto ao público do festival, uma pesquisa de opinião, a qual seria posteriormente utilizada como base para determinar o projeto editorial de uma nova publicação mensal sobre música e comportamento jovem, assim, surge à revista Bizz.

Também nesse mercado, a segmentação mostra-se mais eficaz que a tentativa de falar com muitos leitores ao mesmo tempo. No caso da música, por exemplo, quem gosta de Rock não quer saber de MPB e vice-versa. E quem gosta de Rock pesado não quer saber de baladinhas. E por aí vai... (SCALZO, 2009, pg. 36)

O projeto gráfico foi espelhado no Layout da revista Inglesa Smash Hits 3. Podemos dizer que a revista Bizz passou por três períodos, marcada pelas trocas de equipes editoriais, por reedições de conteúdo e estética, mudanças de projeto gráfico e novas logotipias, assim, definindo os anos de 1985, 1989, 1995 e 2000 e 2007, como marcos históricos da revista.

Apesar de, ao longo dos anos, inúmeras iniciativas tenham mantido o projeto da revista Bizz vivo, em julho de 2007, foi às bancas a última edição da revista Bizz, trazendo na capa a cobertura da última turnê da banda Los Hermanos $^{4}$.

3 Revista Inglesa de conteúdo musical. Durou de 1978 à 2006, mantendo os serviços de rádio e televisão

digital, bem como o website. (Disponível em: <http://electrico8o.blogspot.com/2007/09/ best-of-smash-hits-80s.html>. Acesso em: 24 out. 2011);

4 O Los Hermanos se formou no Rio de Janeiro... Integrantes da banda são Marcelo Camelo, Rodrigo Amarante, Bruno Medina e Rodrigo Barba... Laçaram um dos melhores discos de rock, o 'Bloco do Eu Sozinho', a banda é um dos principais nomes do rock Bra- 


\subsection{PEARL JAM, UM BREVE HISTÓRICO}

No ano de 1984, na cidade de Seattle, EUA, em pleno início do Movimento Grunge ${ }^{5}$, quatro amigos se reuniram para formar uma banda: o guitarrista Stone Gossard, o baixista Jeff Ament, o guitarrista Steve Turner e o vocalista Mark Arm, e colocaram o nome de Green River. Em 1988, a banda se separar, sendo que Steve Turner e Mark Arm fundaram, posteriormente, outra banda, a Mudhoney ${ }^{6}$. Já Jeff Ament e Stone Gossard se reuniram ao vocalista Andrew Wood, para formarem a Mother Love Bone? .

Em seguida ao lançamento do segundo álbum da banda, Andrew Wood morre devido a uma overdose de heroína, e assim a Mother Love Bone de desfaz. Ao final do ano de 1989, e início de 1990, Jeff e Gossard resolvem montar uma nova banda. Chamam para a guitarra Mike McCready, advindo de uma banda chamada "Shadow", e, por indicação do amigo e ex-baterista do Red Hot Chilli Peppers ${ }^{8}$, Jack Irons, Jeff e Stone encontram Eddie Vedder.

Natural do estado de Illinóis, mas naquele momento trabalhando em uma indústria de petróleo e morando em San Diego, no estado da Califórnia, EUA, Eddie Vedder recebeu uma fita cassete com a gravação instrumental, feita por Jeff e Gossard, de três musicas, e assim, "reza e lenda" que

Vedder ouviu as canções instrumentais da fita por várias vezes e saiu para surfar. Foi nessa hora que surgiu a ideia das letras para completar as músicas. Ele gravou os vocais sobre a base instru-

sileiro. (Disponível em: <http://www.loshermanos.blogger.com.br/banda.htm>. Acesso em: 26 out. 2011)

5 Como uma "comunhão" entre interesses, tem-se configurados fatores que impulsionaram a juventude a criar seus próprios escapes (substrato da formação de bandas como Soundgarden e Pearl Jam), voltando-se, em manifesto, contra a cultura liberal de homogeneização e ao consumo massivo de produtos midiatizados. Surge o "Grunge". A morte do vocalista da banda Nirvana, Kurt Cobain, em sete de abril de 1994, por suicídio, é dada pela imprensa do mundo inteiro, como sendo fato que caracteriza o Movimento Grunge e que, de certa forma, reivindica o seu término ideológico. Isso se dá pela banda ter sido ícone, de certa forma, comercial, desse movimento sociocultural que envolveu o Grunge.

6 Banda símbolo, existente até os dias atuais, que junto ao Soundgarden e Nirvana, constituiram o Movimento Grunge de Seattle;

7 Banda Grunge que chegou a lançar dois álbuns, Shine (1989) e Apple (1990);

8 Banda formada em 1983 na Califórnia, EUA, pelo vocalista Anthony Kiedis e o baixista Flea. Na formação atual ainda fazem parte Chad Smith na bateria e o guitarrista Josh Klinghoffer. A banda ainda está atuando e lançou seu álbum mais recente em 2011; 
mental, nomeou as três músicas de 'Alive' (originalmente chamada de 'Dollar Short'), 'Once' e 'Footsteps'9 e mandou a fita de volta. (Disponível em: <http://www.pearljambrasil.com/bio.php>. Acesso em: 09 out. 2011).

Com essa formação, o Pearl Jam fez seus primeiros shows. O nome da banda foi uma ideia do vocalista Eddie Vedder, a partir de uma geleia (em inglês Jam) alucinógena, que sua Vó (Pearl) fazia. Em 1991, a banda assina um contrato com a gravadora Epic, e em agosto do mesmo ano lança seu primeiro álbum, intitulado Ten. A partir desse primeiro trabalho, o Pearl Jam, engendra uma carreira de sucesso global, alcançando o topo das paradas musicais consideradas de maior relevância no meio musical. Até os dias de hoje, o Pearl Jam já lançou mais de 70 trabalhos, entre LP's e Bootlegs ${ }^{10}$ e diversos materiais em vídeo entre videoclipes, DVD e VHS, e diversas participações em discos de outros artistas.

\section{ESTUDOS CULTURAIS: UMA ABORDAGEM EM DOUGLAS KELLNER}

Os estudos culturais surgem a partir de uma diversidade de interlocuções teórico/críticas ligadas às mais diversas áreas do conhecimento, como a política, a crítica literária, a linguística e a sociologia (em seus aspectos culturalistas e interacionistas), a antropologia, aos estudos da mídia, o cinema e a cultura popular. Em síntese, a teia de interações entre cultura, sociedade e história compõe o centro dos interesses analíticos dos estudos culturais ${ }^{11}$. Os ensaios produzidos, no final dos anos 50, por Richard Hoggart, Raymond Williams e Edward Thompson, são identificados como substratos teóricos na origem dos Estudos Culturais.

Em vista disso, os caminhos teóricos do pesquisador Douglas Kellner, perpassam pelas leituras de Karl Marx, Friederich Nietchz e Sigmund Freud, pela graduação em Filosofia, pelo engajamento no movimento estudantil

9 Once e Alive são composições que entraram no repertório do primeiro disco, Ten, já Footsteps veio entrar no repertório de um cd promocional, lançado no Brasil muito tempo depois do lançamento nos EUA;

10 Registros em CDs promocionais dos shows realizados em torno do mundo;

11 Segundo Agger (1992), fica evidente em relação àqueles [os estudos culturais]: a heterogenia varia conforme aspectos sócio-históricos, e não se resume aos intertextos dos seres humanos, às suas experiências e informações adquiridas. (CRUZ, 2006, pg.65) 
a partir de 68, além da militância na New Left' ${ }^{12}$, e das influencias de E. P. Thompson, Raymond Williams e Richard Hoggart, da escola britânica de estudos culturais. Ao estudar na Europa, Kellner conheceu os principais autores da escola de Frankfurt, como Adorno e Horkheimer, aprofundando ainda mais seus estudos em Teoria Crítica, juntando, mais tarde, a graduação em Filosofia, e assim formando o cerne principal de seu referencial teórico.

Douglas Kellner traz à luz dos estudos culturais, pressupondo um estudo crítico da mídia, aliando critérios multiculturais e multiperspectivicos, em uma análise política ideológica frente às dinâmicas de embate e construção social, uma possibilidade de se fazer uma reflexão concreta em torno dos textos e ideologias da cultura da mídia, promovendo um diálogo contextual e de relação.

Em análise, torna-se importante, dentro dessa realidade de estudo, se fazer uma contextualização histórico/crítica, no intuito de se ter melhor compreensão do meio e da mensagem propostos pelo veículo, assim como ilustrar a forma como é construída, por exemplo, a notícia no âmbito do jornalismo.

Quando é proposta uma discussão com base em uma análise histórico/ crítica cultural dos produtos e textos da mídia, há que se fazer sob a ótica de contextualização e relação, assim deixando expostas as interações, contraposições, embates e reflexões em nível sócio/político, determinando o papel dos atores e grupos sociais hegemônicos e de resistência. Segundo Kellner (2001), a partir dessas relações, ficam claros os movimentos e dinâmicas de manipulação dos produtos midiáticos, a favor de posições ideológicas dominantes, ou contra-hegemônicas.

A crítica diagnóstica ${ }^{13}$ feita a partir dos textos extraídos da cultura da mídia, pressupondo, segundo Kellner, uma análise com base política, his-

\footnotetext{
12 Movimento que teve início na Inglaterra em 1956, após o célebre discurso do líder soviético Nikita Kruchev, no XX Congresso do Partido Comunista da União Soviética, denunciando as iniqüidades cometidas durante o período stalinista. Acontecimento teve forte repercussão entre os ingleses filados ao Partido Comunista e foi decisivo para a saída da agremiação de intelectuais como: Eric Hobsbawm, Rodney Hilton, E. P. Thompson e Raymond Williams. Os dois últimos são considerados, juntamente com Richard Hoggart, os fundadores dos Estudos Culturais britânicos, tão influentes nos trabalhos de Douglas Kellner. (LEITE, 2004, pg. 5)

13 A crítica diagnóstica [...] deve pressupor uma dimensão de profundidade nesse tipo de cultura e usar métodos de interpretação de mitos e símbolos para trazer à tona significados ocultos, latentes e subliminares. (KELLNER, 2001, pg. 151).
} 
tórica e contextual, tem o fim de desnudar os aspectos ideológicos que alicerçam os discursos e textos culturais a que se propõe aplicar os estudos culturais críticos.

O estudo cultural crítico, proposto por Kellner, arca com uma análise política da cultura, diagnosticando a presença de forças de dominação e resistência ideológicas, que regem a dinâmica social. Além dessa visão política, os fatores históricos, de relação, contextuais, ideológicos e ambientais, caminham ao encontro das categorias descritivas com propósito de delinear as experiências e práticas no campo social, articulando o contexto vinculado à linguagem e às expressões próprias da cultura, e compondo, através da personificação dos discursos e da customização das atitudes sociais, um quadro de análise crítica que esboça os anseios pretendidos pelo trabalho em questão.

\section{METODOLOGIA}

A proposta do presente trabalho é a de interpelar criticamente, a partir das categorias de análise pontuadas por Douglas Kellner (Horizonte Social, Campo Discursivo e Ação Figural), duas matérias jornalísticas, extraídas das edições de Julho de 1992 e Dezembro de 1993 da revista Bizz, levando em consideração que ambas as matérias, publicadas nessas edições, deram destaques de capa à banda Pearl Jam. Os pressupostos, a partir de uma apreciação qualitativa, que levaram a escolha das edições da revista Bizz (o ano, as edições e o tipo de texto jornalístico), como um dos objetos de análise, foram: a longevidade, a cobertura dispensada pela revista (referente aos anos de maior fomento do Movimento Grunge de Seattle) e ao início da carreira da banda Pearl Jam (primeira metade da década de 90).

\section{CATEGORIAS DE ANÁLISE}

O horizonte social compõe uma categoria de análise, que traz embutida o estudo histórico, com vistas a elucidar aspectos de fundo contextuais, em âmbito político, econômico, cultural e social, que permeiam as relações na sociedade. No Campo Discursivo, encerram-se os objetos, os agentes e seus discursos, ou seja, "todos os elementos (hegemônicos e contra-hegemônicos, superiores e inferiores) envolvidos no discurso dos meios de comunicação." (CRUZ, 2006, pg. 95-96). A Ação Figural complementa e fundamenta as análises desse trabalho, no ponto em que entrecruza con- 
texto histórico, análise dos objetos discursivos e suas retóricas e deixa em aberto a possibilidade de, através da interdisciplinaridade, a que se propõe os estudos culturais críticos, substanciar a discussão em torno da interpretação, subsidiada pelo aspecto qualitativo da pesquisa que aqui se propõe.

\title{
6 ANÁLISES
}

\subsection{Descrições da edição 84}

A publicação de julho de 1992, edição 84, da revista Bizz, traz em sua capa uma foto do vocalista da banda Pearl Jam, Eddie Vedder, em plena ação, em um dos shows da banda, e como manchete: "Na estrada com Pearl Jam, o susto do sucesso". A matéria no interior da revista se encontra entre as páginas 20 a 25, e é intitulada como "Mistério no rádio", fazendo uma referência a emergência da banda de Seattle, e questionando o seu gênero e estilo, mediante comparação com outra banda de Seattle, Nirvana.

No início da matéria, ao longo dos seis primeiros parágrafos, é narrando um episódio ocorrido em um dos shows da banda.

\begin{abstract}
Apenas uma mensagem pessoal do vocalista do Pearl Jam, [...], para um fã londrino ensandecido cujo stage-diving machucou a galera da frente do palco. Esse tipo de coisa deixa Vedder possesso. Então, quando o animal subiu no palco para pular de novo, Vedder não deixou barato e mostrou de uma maneira bem pessoal que ele detesta esse tipo de coisa (BIZZ, 1992, pg. 22)
\end{abstract}

O comentário publicado pela revista, dado pelo baixista, a cerca do ocorrido é sarcástico e brincalhão. Já Vedder expõe que o problema não está em fazer stage-diveng, mas sim quando tem a possibilidade de machucar alguém na plateia. A matéria expõe fatos que elevam a banda ao status de celebridade comercial, a partir do momento em que cita o fenômeno de consumo que se abateu sobre a mesma, sublinhando a presença massiva de público nos shows e a procura dos veículos midiáticos, o que já se fazia sufocante.

A partir desse momento, a matéria traz à superfície o questionamento sobre a história da banda, sua origem. A narrativa passa então para a descrição do momento atual (em 1992) para a banda, com o primeiro álbum recém-lançado, shows periódicos e turnê internacional. Traz a perspectiva dos 
integrantes da banda em torno do sucesso e os fatos e atitudes que passam a ser registros de momentos e marcas características, que identifica a banda até os dias atuais.

O texto da matéria passa a descrever sobre o "transe catártico" em que os fãs entram ao ouvirem as músicas do Pearl Jam. Em um segundo momento, a narrativa passa a descrever o comportamento da banda no palco durante os shows, principalmente o de Vedder, que, assim como a plateia, também entra em um determinado transe. A narrativa descreve Vedder como um "junkie de adrenalina", e o resultado de todo esse "agito" promovido pela banda ao longo dos shows, são escoriações leves, arranhões e dentadas.

Posteriormente, o texto faz referências às opiniões dos críticos da época, com relação ao Pearl Jam, rotulando o comportamento da banda como sendo "típica de rock de arena". A matéria se volta a outro olhar, considerando que a música feita por bandas como o Pearl Jam, há um tempo (faz referência há um ano antes de 1992), estariam relegadas a apenas circular nos circuitos universitários.

A matéria traz o depoimento de cada integrante da banda, discorrendo sobre o sucesso, de certa forma, prematuro, que a banda estava vivenciando. Relata, também, o apego do público à banda, assim desvendando a linha condutora da matéria, que busca, a partir do título e texto complementar, expressar o fenômeno de público em torno da banda Pearl Jam.

Nos últimos parágrafos, o texto da matéria explicita a contrapartida que a banda dá para seus fãs, exaltando uma conexão real entre os dois lados, fazendo referências às tatuagens feitas pelos fãs, às fotos tiradas do público por Vedder durante o show, com sua maquina Polaroide, imortalizando esse momento catártico de um "transe quase alucinógeno".

\subsection{DESCRIÇÕES DA EDIÇÃO 101}

A edição 101, da revista Bizz do ano de 1993, traz uma foto do vocalista Eddie Vedder em preto e branco, em contraste com um fundo amarelo, em sua capa a manchete diz: "Pearl Jam, Eddie Vedder está pirando", fazendo referência a uma crise gerada pelo sucesso inesperado, levando a banda, e principalmente o vocalista, a tomar atitudes de repúdio à imprensa massiva. A matéria produzida pela revista ocupa a parte central da publicação, e traz 
como título: “O sucesso é uma merda”.

Em uma primeira parte, o enfoque é dado para um fato ocorrido, em que o vocalista Eddie Vedder teria pulado do palco em cima dos seguranças, para contê-los, por estarem batendo em um fã que teria tentado subir ao palco. O acontecimento foi durante um show no Festival de Roskilde ${ }^{14}$, na Dinamarca, em junho de 1992. Abrindo o texto, os integrantes da banda são questionados sobre o fato ocorrido e Vedder responde usando uma metáfora: "Naquele show, eu me despedacei." As sequências de perguntas ainda permeiam o ocorrido em Roskilde, deixando o vocalista da banda Pearl Jam incomodado. A próxima pergunta é curta e direta: questiona se ele havia perdido o controle naquele momento em que ocorreu a briga. Como resposta, o vocalista diz que o perde a toda hora.

A matéria, nesse momento, traz um subtítulo "O sucesso deve ter fundido ${ }^{15}$ a cabeça dele", e parte para o questionamento sobre o sucesso e suas consequências, assim, tecendo, em princípio, uma narrativa que descreve o comportamento de Eddie Vedder, ao fazer uso abusivo de bebidas alcoólicas, e se encontrar propenso a atos de violentos. No próximo parágrafo, a matéria traz um levantamento de todos os méritos atingidos pela banda desde o lançamento do primeiro álbum, descrevendo as cifras milionárias atingidas com as vendas do mesmo, ultrapassando as do álbum de estreia da banda Nirvana, Nevermind.

O texto, então, usa essas conquistas da banda para justificar a popularidade atingida pelo Pearl Jam, argumentando que Vedder teria se tornado, assim, um porta-voz daquela geração. Em contrapartida, o texto expõe uma situação de briga entre os integrantes da banda Nirvana e Pearl Jam, incitada, inicialmente, por um comentário dado pelo vocalista Kurt Cobain. Ament declara, de forma neutra, que nenhum dos integrantes do Pearl Jam conhece qualquer integrante do Nirvana, por isso, não teriam como expor uma opinião pessoal.

Com o subtítulo “Um álbum caótico", a matéria direciona o foco para o lançamento do segundo álbum da banda (Vs.), e nos parágrafos subsequentes discorre sobre as controvérsias em torno da escolha do nome para o álbum, assim como faz uma crítica descritiva, direta, em torno das músi-

\footnotetext{
14 Um dos 3 maiores festivais de música da Europa, realizado no município de Roskilde, a $30 \mathrm{Km}$ de Copenhague, na Dinamarca.
}

15 Palavra em substituição a um palavrão; 
cas do álbum, expondo que, "as canções do novo disco são violentas, ameaçadoras." (BIZZ, 1993, pg. 39). O texto segue com trechos da entrevista concedida pela banda, em que Eddie Vedder responde a questionamentos direcionados ao conceito e produção do álbum Vs.. Vedder demonstra confiança no trabalho feito na produção e gravação dos dois álbuns (Ten e Vs.).

Outro subtítulo traz a seguinte chamada, "Os tiras de Seattle", e narra a história por trás da música "Policeman". Vedder narra um ocorrido com ele e um amigo que é indigente, o qual foi abordado de forma hostil pela polícia. Contaminado com a cena que havia presenciado, compôs e gravou a música. Na última parte da matéria, o subtítulo "Me chama de animal”, faz referência à canção "Animal”. A narrativa descreve a apresentação de Pearl Jam na premiação da MTV norte americana, no ano de 1992.

\subsection{HORIZONTE SOCIAL}

Sob a ótica do Horizonte Social, que "refere-se às experiências, às práticas e aos aspectos reais do campo social que ajudam a estruturar o universo da cultura da mídia e sua recepção" (KELLNER, 2001, pg. 137), pode-se remontar o pano de fundo que caracteriza tanto os fatores de transformação e reinteração do projeto editorial da revista Bizz, assim como podemos vislumbrar os acontecimentos que permearam a banda Pearl Jam em sua trajetória, tomando como período de observação o início dos anos 90.

O contexto histórico, do início da década de 90, traz a globalização, na esfera cultural, como um processo de massificação e homogeneização, sendo evidenciada, principalmente, através da "catarse" midiática promovida pelo avanço dos meios de comunicação, em especial a televisão. Os produtos midiáticos, veiculados pela televisão e pelas rádios comerciais, os filmes e a música, são os substratos para a popularização dessa cultura importada. A Bizz, ao longo dos anos de 1992 até 1995, enfrenta altos e baixos, devido à crise financeira gerada pela era Collor, a troca da gestão presidencial, o fôlego gerado pelo plano real e a queda da concorrência especializada.

No ano de 1992, a banda Pearl Jam colhia os louros do primeiro álbum, o recém lançado Ten ${ }^{16}$, fazendo pequenas turnês, abrindo shows para bandas como Alice in Chains e Soundgarden. No mesmo ano, ainda surgiu a banda tributo a Andy Wood, Temple of the Dog. Em Março de 92, a banda foi con- 
vidada para realizar o programa "MTV Unplugged", popularizado no Brasil como "Acústico MTV". A participação da banda no Loolapallosa, 1992, elevou o Pearl Jam ao status de sucesso e reconhecimento de público. Ao longo do ano de 1993, o Pearl Jam excursionou com o show de lançamento do primeiro álbum, Ten, ao mesmo tempo em que passou a compor novas músicas que, no futuro, iriam fazer parte o setlist do seu segundo álbum, chamado Vs. (versus).

\subsection{CAMPO DISCURSIVO}

Tendo como fundo histórico o início de uma década em que, política e economicamente, o ambiente social é afetado por crises, tanto no Brasil, quanto nos EUA, os fatores discursivos, expressos pela revista e pela banda, manifestam-se como consequência do processo de globalização, pois os aspectos que implicam em reificar os símbolos midiáticos, tornando-os universais, contrastam com a realidade evidenciada no cotidiano, afetando, assim, o transcurso e o comportamento naquele período.

A revista Bizz, em seu texto, argumento e ideologia, transparece um discurso e atitude que se modifica ao longo do tempo, sendo adequado aos paradigmas do processo de globalização, em que se produz uma cultura da mídia diretamente atrelada aos aspectos comerciais, e onde se constroem mitos e celebridades, direcionando tendências e edificando a moda.

O discurso do Movimento Grunge, pronunciado e customizado pela banda Pearl Jam, transparece uma preleção característica, própria daquela geração, daquele momento histórico. As particularidades contextuais, articulando atitudes e comportamentos, e a linguagem característica, que reproduz as ideias expressas na fala dos personagens da narrativa, no caso a banda Pearl Jam, deixam transparecer os conflitos existentes no intertexto dessa pesquisa, desenhando, assim, o objetivo do trabalho aqui proposto.

Em 1992, a banda Pearl Jam despontava para o sucesso, em termos de cifras, associadas às vendas de seu primeiro álbum (cerca de nove milhões em todo o mundo), à grande quantidade de shows e aparições na TV e o assédio intermitente dos fãs e da imprensa. Assumir o status de celebridade, àquela época de escalada da globalização e consequente transformação das pessoas em mitos, formatou a banda em um produto comercial a ser esgotado em suas potencialidades artísticas, ignorando a personalidade das pessoas por trás da famosa fachada. 
Os integrantes da banda têm a consciência de que a evidência como celebridade, desfrutando dos holofotes da mídia, com a oportunidade de aparecer de forma massiva através dos veículos de comunicação, é de fundamental importância, e assim chamam a responsabilidade para si. Essas atitudes são próprias da banda, ou seja, o Pearl Jam sempre esteve associado a alguma causa social, fazendo questão de tocar em shows beneficentes, participar de coletâneas para angariar fundos, e até mesmo protestando, de alguma forma, em seus próprios shows, tentando passar uma mensagem de ajuda humanitária ao seu público.

\subsection{AÇÃO FIGURAL}

Na edição 84, referente ao mês de julho de 1992, a matéria, que trás como pauta a banda Pearl Jam, os anuncia como um mistério no rádio, tentando decifrar quem é essa nova banda de Seattle, que desponta como ícone e espelho discursivo de uma geração. Ao longo de toda a construção textual da matéria, fica claro a intenção de se fazer um raio-x da banda, a partir das evidências em torno do sucesso de vendas do primeiro álbum, da lotação e circuito extenso de shows e da cobertura dispensada pela mídia mundial à mesma. A matéria atua de forma descritivo-narrativa, trazendo o testemunho dos integrantes da banda, para ratificar o perfil traçado pela mesma, e, a partir dos fatos narrados e conduzidos por uma linha de raciocínio que deixa clara uma aproximação com determinada neutralidade jornalística, justifica constituir-se de uma primeira impressão, publicada pela revista Bizz, em relação à banda Pearl Jam.

A edição 101, referente ao mês de dezembro de 1993, também trás em sua capa o vocalista da banda Pearl Jam, Eddie Vedder. Porém, o contexto que permeia a matéria publicada, revela-se no título, em que se afirma que o vocalista está "pirando". Em uma análise de conteúdo, pode-se dizer que a matéria "direcionou" o foco do argumento para os fatos mais polêmicos levantados sobre a banda até àquele momento. O conteúdo e forma com a qual as perguntas foram direcionadas aos integrantes da banda adquirem um caráter de insistência. A pauta da matéria volta seu olhar para os fatos isolados que repercutem na mídia massiva, como brigas, tumultos, discussões e provocações, ocultando os motivos pelos quais esses fatos acontecem e sem demandar mais atenção a questões envolvendo a carreira musical da banda. 
Levando em consideração que, naquela ocasião, o Pearl Jam encontrava-se em um limiar de exaustão, devido à cobrança gerada pela demanda de projetos, shows e aparições midiáticas, e também à decisão da banda pela redução de seus esforços comerciais, tornou-se notória a apatia da mesma em entrevistas, principalmente as de cunho sensacionalista.

\section{CONSIDERAÇÕES FINAIS}

O presente trabalho procura trazer à tona alguns aspectos dentro dos estudos em comunicação, com ênfase nos estudos culturais críticos, tendo como referencial teórico as categorias de análise determinadas por Douglas Kellner. A partir dessa fundamentação teórica, os estudos se voltam a determinar de que forma a revista Bizz publicou, em termos de conteúdo, as matérias cuja pauta repousa sobre a banda Pearl Jam. A abordagem temática, a forma de escrita, as intenções frente ao direcionamento do foco do assunto, o teor contextual que permeia a época em que as matérias foram editadas, o discurso de cada interlocutor envolvido nesse contexto de estudo e suas interpelações textuais, são, de forma implícita, componentes fundamentais na observação e análise para essa pesquisa.

O discurso da banda Pearl Jam, analisado até o momento, contextualiza suas atitudes frente aos veículos de comunicação. Observa-se que a banda, de certa forma, acabou sendo tragada pela maré da explosão midiática, que no início dos anos 90, partindo das premissas do processo de globalização da cultura e por consequência da mídia, através de veículos como a TV, as rádios comerciais, a internet (em seu princípio), e no caso do presente trabaIho, as revistas especializadas, os colocaram em evidência como ícones de um movimento, o retrato de uma geração, modelos de linguagem e moda, atrelados ao movimento Grunge.

Enquanto a banda discursa, sobre bases ideológicas singulares a seus modos de ver a vida, compondo músicas de cunho revolucionário e ao mesmo tempo melancólico, a realidade que permeia a "reificação" de ícones e símbolos, dentro da perspectiva de massa, promovida pela mídia, os transforma em produtos da cultura da mídia, rotulando-os e analisando-os sob uma perspectiva comercial, assim, o Pearl Jam virou marca registrada. $\mathrm{Na}$ matéria da edição 84, verifica-se uma preocupação por parte da revista em apresentar, descritivamente, a banda ao público, narrando suas histórias, sua relação com a plateia, utilizando-se das impressões emitidas pelos pró- 
prios, a partir de entrevista, ratificando o discurso emitido pela própria revista. Na edição 101, a abordagem toma forma, no questionamento dos fatos, consequentes das evidências de um processo de exaustão da banda, as explosões violentas por parte do vocalista nos shows, a postura de afastamento da mídia.

A revista Bizz traçou sua rota em direção à construção de uma linguagem cada vez mais adequada a Globalização, deixando de lado os textos descritivo-explicativos (caso da edição 84), para assumir uma narrativa que, em muitos pontos, exclui os "comos" e "porquês", frente aos acontecimentos que permearam a banda Pearl Jam naquele momento, naquela época, a partir daquele discurso despendido por ambos (caso da edição 101). Identifica-se uma modificação em termos editoriais, de uma revista para outra, detectando, na construção textual de ambas, valores que, ao longo do tempo, de 1992 para 1993, assumem características próprias do processo de globalização, exaltando o espetáculo em detrimento da informação.

\section{REFERENCIAIS}

BIZZ: Edição dupla de aniversário. São Paulo: Ed. Azul, n. 84, jul. 1992.

BIZZ. São Paulo: Ed. Azul, n. 101, dez. 1993.

CRUZ, Fábio Souza da, A cultura da mídia no Rio Grande do Sul,: o caso MST e Jornal do Almoço, Pelotas: EDUCAT, 2006

ESCOSTEGUY, Ana Carolina Damboriarena. Cartografias dos Estudos Culturais - Uma versão latino-americana. Belo Horizonte, MG: Autêntica, 2001, 240 pg.

GOSSARD, Stone.; VEDDER, Eddie. Even Flow. Intérprete: Pearl Jam. In: Pearl Jam. Ten. Seattle, WA: Epic, p1992.1 CD. Faixa 2.

HALL, Stuart, A identidade cultural na pós-modernidade, Rio de Janeiro, DP\&A, 2000.

KELLNER, Douglas. A Cultura da mídia - estudos culturais: identidade e política entre o moderno e o pós-moderno. Bauru, SP: EDUSC, 2001

LEITE, Sidney Ferreira. Reflexões sobre comunicação e sociedade: as contribuições de Douglas Kellner. Revista eletrônica: e-compós, 2004. Disponível em: <http://www.compos.org.br/e-compos>. Acesso em: 12 out. 2011.

VEJA 25 anos: retrospectiva de um quarto de século. São Paulo: Ed. 1311, 27 out. 1993. 168 p.

MARSHALL, Leandro, O jornalismo na era da publicidade, São Paulo: Summus, 2003;

MATTELART, Armand e Michèle, História das teorias da comunicação, São Paulo: Edições Loyola, $12^{\mathrm{a}}$ edição, 2009; 
A COBERTURA DA REVISTA BIZZ SOBRE A BANDA PEARL JAM: UMA ANÁLISE SOB A ÓTICA DOS ESTUDOS CULTURAIS

PILETI, Nelson. História do Brasil, da pré-história do Brasil aos dias atuais. São Paulo:

Ática, $11^{a}$ edição, 1990;

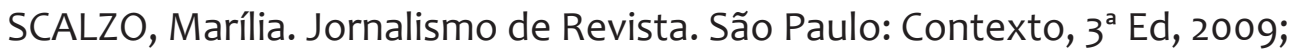

HYPE! 1996. Direção: Doug Pray. Produção: Steven Helvey. Seattle, USA: Lion Gate Enterteinment, 1996. DVD (84 min.).

TRAQUINA, Nelson. Teorias do jornalismo. A tribo jornalística - uma comunidade interpretativa transnacional. Florianópolis: Insular, $2^{a}$ ed., 2008.

RECEBIDO EM: 15/05/2015

ACEITO PARA PUBLICAÇÃO: 03/08/2015 


\section{Márcio Farias de Mello}

Natural de ljuí, RS, Possui graduação em Ciências Biológicas pela Universidade Federal de Pelotas (2001) e Jornalismo pela Universidade Católica de Pelotas (2012). Lecionou durante 9 anos em cursos preparatórios. Atualmente exerce a função de Locutor/Operador na Rádio Atlântida Zona Sul.

\section{Fábio Souza da Cruz}

Possui graduação em Comunicação Social - Jornalismo e Publicidade e Propaganda pela Universidade Católica de Pelotas (1997), especialização em Teoria do Jornalismo e Comunicação de Massa pela Pontifícia Universidade Católica do Rio Grande do Sul (1998), mestrado em Comunicação e Práticas Sócio-Políticas pela Pontifícia Universidade Católica do Rio Grande do Sul (2000), doutorado em Cultura midiática e Tecnologias do Imaginário pela Pontifícia Universidade Católica do Rio Grande do Sul (2006) e pós-doutorado em Direitos Humanos, Mídia e Movimentos Sociais pela Universidade Pablo de Olavide (Sevilha / Espanha - 2011). Atualmente é professor adjunto do curso de Jornalismo da Universidade Federal de Pelotas. Foi professor da Universidade Católica de Pelotas nos cursos de graduação em comunicação social e mestrado em Política Social. 
